\title{
Correction for Mechanical Dead Space in the Calculation of Physiological Dead Space
}

\author{
Gloria J. Singleton, C. Robert Olsen, and Richard L. Smith \\ From the Chest Section of the Medical Service, Veterans Administration \\ (Wadsworth) Hospital and University of California at Los Angeles School \\ of Medicine, Los Angeles, California 90073
}

\begin{abstract}
A в S T R A C T When physiological dead space $\left(V_{D_{\mathrm{P}}}\right)$ is calculated for a patient who has alveolar dead space, e.g., after pulmonary vascular occlusion, less than the full volume of attached mechanical dead space $\left(V_{D_{m}}\right)$ appears in the measured dead space $\left(V_{D_{n}}\right)$. Under these conditions the traditional subtraction of $V D_{m}$ from $V D_{n}$ leads to underestimation of $V_{D_{p}}$ and can give a falsely small ratio of $\mathrm{VD}_{\mathrm{p}}$ to tidal volume (VT) when, in fact, an abnormally large $\mathrm{VD}_{\mathrm{p}} / \mathrm{VT}$ exists. To make the proper correction for $V D_{m}$, two equations have been derived and validated with seven subjects having $\mathrm{VD}_{\mathrm{p}} / \mathrm{VT}$ from 0.29 to 0.87 , using $V_{D_{m}}$ 's from 120 to $322 \mathrm{ml}$. With only a small modification, these equations are suitable for routine clinical use and give $\mathrm{VD}_{\mathrm{p}} / \mathrm{VT}$ within 0.02 of that by the validated equations ( 32 of 33 comparisons). The fraction of $V_{D_{m}}$ subtracted from $V D_{n}$ is the square of the ratio of effective alveolar to total alveolar ventilation and is never $>1$. This fraction is $\left(\mathrm{PACO}_{2} / \mathrm{PaCO}_{2}\right)^{2}$, where $\mathrm{PACO}_{2}$ and $\mathrm{PaCO}_{2}$ are the mean partial pressures of expired alveolar and of arterial $\mathrm{CO}_{2}$; in the other equation this fraction is $\left[\mathrm{PECO}_{2} / \mathrm{PaCO}_{2}\left(\mathrm{VT}-\mathrm{VD}_{\mathrm{D}_{\mathrm{an}}}-\mathrm{VD}_{\mathrm{m}}\right)\right]^{2}$ where $\mathrm{PE}_{\mathrm{CO}_{2}}$ is mixed expired $\mathrm{PCO}_{2}$ and $\mathrm{VD}_{\mathrm{an}}$ is anatomical dead space. The second equation requires an estimated $\mathrm{VD}_{\mathrm{an}}$ and is applicable when $\mathrm{PACO}_{2}$ is not measured or does not plateau (as in exercise).
\end{abstract}

\section{INTRODUCTION}

Physiological dead space $\left(V_{D_{p}}\right)^{1}$ is becoming a more useful index of impaired perfusion of pulmonary vessels

A preliminary report of this work has appeared in abstract form. (Singleton, G. J., R. L. Smith, R. L. Trager, and C. R. Olsen. 1969. Phy'siologist. 12: 356.)

Received for publication 11 April 1972 and in revised form 14 July 1972.

${ }^{1}$ Abbreviations used in this paper: $\mathrm{f}_{\mathrm{p}}$, fraction of ventilation to perfused alveoli; $\mathrm{FACO}_{2}$, mean concentration of $\mathrm{CO}_{2}$ in expired alveolar gas; $\mathrm{FE}_{\mathrm{CO}_{2}}$, concentration of $\mathrm{CO}_{2}$ in mixed expired gas; $\mathrm{PACO}_{2}$ mean partial pressure of $\mathrm{CO}_{2}\left(\mathrm{PCO}_{2}\right)$ in as normal values and conditions for $\mathrm{VD}_{\mathrm{p}}$ become more precisely defined (1). When a normal adult breathes spontaneously at a normal tidal volume $(\mathrm{VT}), \mathrm{VD}_{\mathrm{p}} / \mathrm{VT}$ is $<0.45$ and decreases with increased $\operatorname{VT}(1,2)$. $\mathrm{VD}_{\mathrm{p}} / \mathrm{VT}$ may increase with age (1) and with a variety of parenchymal lung diseases. However, a very large ratio (e.g., 0.8 at a normal VT) or an increase of this ratio with the increased VT of exercise (2) supports the diagnosis of pulmonary vascular occlusion.

In the traditional calculation of $\mathrm{VD}_{\mathrm{p}}$, all of the mechanical dead space $\left(V_{D_{m}}\right)$ is subtracted from the measured dead space $\left(V_{D_{n}}\right) .^{2}$ As given in Enghoff's modified Bohr equation (3),

$\mathrm{VD}_{\mathrm{p}}=\mathrm{VD}_{\mathrm{n}}-\mathrm{VD}_{\mathrm{m}}=\frac{\mathrm{Pa}_{\mathrm{CO}_{2}}-\mathrm{PE}_{\mathrm{CO}_{2}}}{\mathrm{PaCO}_{2}} \cdot \mathrm{VT}-\mathrm{VD}_{\mathrm{m}}$,

where $\mathrm{Pa}_{\mathrm{CO}_{2}}$ and $\mathrm{PE}_{\mathrm{CO}_{2}}$ are the partial pressures of $\mathrm{CO}_{2}$ in arterial blood and mixed expired gas, respectively. Suwa and Bendixen have analyzed the change of $\mathrm{Pa}_{\mathrm{CO}_{2}}$ with added $V_{D_{m}}$ and have shown that total subtraction of $V_{D_{m}}$ can lead to underestimation of $V_{D_{p}}(4)$. This underestimation occurs whenever gas from $V_{D_{m}}$ is inspired into nonperfused alveoli where it has no direct effect on gas exchange with alveolar capillary blood.

We have derived and validated two equivalent equations for making the proper calculation and present evidence that shorter modified forms give, with precision $\mathrm{VD}_{\mathrm{p}}$ at the $\mathrm{VT}$ of the measurement $\left(\mathrm{VT}_{\mathrm{n}}\right)$.

expired alveolar gas; $\mathrm{PaCO}_{2}$, mean $\mathrm{PCO}_{2}$ in arterial blood; $\mathrm{PE}_{\mathrm{CO}_{2}}, \mathrm{PCO}_{2}$ in mixed expired gas; $r$, correlation coefficient; $\mathrm{VA}$, effective alveolar ventilation per breath; $\mathrm{VCO}_{2}$, volume of $\mathrm{CO}_{2}$ expired per breath; $\mathrm{VD}_{\mathrm{alv}}$, alveolar dead space; $\mathrm{VD}_{\mathrm{an}}$, anatomical dead space; $V_{D_{m}}$, mechanical dead space; $V_{D_{n}}$, total measured dead space; $\mathrm{VD}_{\mathrm{p}}$, physiological dead space; $\mathrm{VT}$, expired tidal volume.

${ }_{2}$ Subscripts specific for this paper: $\mathrm{n}$, value measured with $\mathrm{VD}_{\mathrm{m}}$ attached; o, value without $\mathrm{VD}_{\mathrm{m}}$ attached. 


\section{METHODS}

Derivation. The volume of $\mathrm{CO}_{2}$ expired in a breath $\left(\mathrm{VCO}_{2}\right)$ is given by

$$
\mathrm{VCO}_{2}=\mathrm{FE}_{\mathrm{CO}_{2}} \mathrm{VT}=\mathrm{FACO}_{2}\left(\mathrm{VT}-\mathrm{VD}_{\mathrm{an}}-\mathrm{VD}_{\mathrm{m}}\right),
$$

where $\mathrm{FE}_{\mathrm{CO}_{2}}$ and $\mathrm{FACO}_{2}$ are the mean concentrations of $\mathrm{CO}_{2}$ in the mixed expired gas and in the expired alveolar gas, respectively, and $V_{D_{\mathbf{a n}}}$ is anatomical dead space. Dividing by $\mathrm{PaCO}_{2} \mathrm{VT}$ and converting concentrations to partial pressures:

$$
\frac{V_{A_{n}}}{V T}=\frac{P_{\mathrm{CO}_{2}}}{\mathrm{PaCO}_{2}}=\frac{\mathrm{PACO}_{2}\left(\mathrm{VT}-\mathrm{VD}_{\mathrm{an}}-\mathrm{VD}_{\mathrm{m}}\right)}{\mathrm{PaCO}_{2} \cdot \mathrm{VT}},
$$

where $V_{A_{n}}$ is measured effective alveolar ventilation per breath.

To derive equations for $\mathrm{VD}_{\mathrm{p}}$, we have assumed that addition of $V_{D_{m}}$ does not change the fraction of ventilation to perfused alveoli $\left(f_{p}\right)$. Using the equation for $f_{p}$ derived by Julian, Travis, Robin, and Crump (5), and denoting, rezpectively, the conditions with and without $V_{D_{m}}$ by " $n$ " and "o":

$$
\begin{aligned}
f_{p}=\frac{\mathrm{PE}_{\mathrm{o}} \mathrm{CO}_{2}}{\mathrm{~Pa}_{0} \mathrm{CO}_{2}-\mathrm{PA}_{\mathrm{o}} \mathrm{CO}_{2}+\mathrm{PE}_{\mathrm{o}} \mathrm{CO}_{2}} \\
=\frac{\mathrm{PE}_{\mathrm{n}} \mathrm{CO}_{2}}{\mathrm{~Pa}_{\mathrm{n}} \mathrm{CO}_{2}-\mathrm{PA}_{\mathrm{n}} \mathrm{CO}_{2}+\mathrm{PE}_{\mathrm{n}} \mathrm{CO}_{2}}
\end{aligned}
$$

Cross multiplying the middle and right sides of equation 4 and dividing by $\mathrm{Pa}_{0} \mathrm{CO}_{2} \mathrm{~Pa}_{n} \mathrm{CO}_{2}$ :

$$
\begin{aligned}
\frac{\mathrm{PE}_{\mathrm{o}} \mathrm{CO}_{2}}{\mathrm{~Pa}_{\mathrm{o}} \mathrm{CO}_{2}}-\frac{\mathrm{PE}_{\mathrm{o}} \mathrm{CO}_{2} \mathrm{PA}_{\mathrm{n}} \mathrm{CO}_{2}}{\mathrm{~Pa}_{\mathrm{o}} \mathrm{CO}_{2} \mathrm{~Pa}_{\mathrm{n}} \mathrm{CO}_{2}} & \\
= & \frac{\mathrm{PE}_{\mathrm{n}} \mathrm{CO}_{2}}{\mathrm{~Pa}_{\mathrm{n} \mathrm{CO}_{2}}}-\frac{\mathrm{PE}_{\mathrm{n}} \mathrm{CO}_{2} \mathrm{PA}_{\mathrm{o}} \mathrm{CO}_{2}}{\mathrm{~Pa}_{\mathrm{n}} \mathrm{CO}_{2} \mathrm{~Pa}_{\mathrm{o}} \mathrm{CO}_{2}} .
\end{aligned}
$$

Substituting the left side of equation 3 (with appropriate subscripts) for the first term on each side of equation 5 , and substituting the right side of equation 3 for $\mathrm{PE}_{\mathrm{CO}_{2}} / \mathrm{PaCO}_{2}$ in the second term on each side of equation 5 :

$$
\begin{aligned}
\frac{V A_{0}}{V T_{0}} & -\frac{\mathrm{PA}_{A_{0}} \mathrm{CO}_{2} \mathrm{PA}_{\mathrm{n}} \mathrm{CO}_{2}\left(\mathrm{VT}_{\mathrm{o}}-\mathrm{VD}_{\mathrm{an}_{\mathrm{o}}}\right)}{\mathrm{Pa}_{\mathrm{o}} \mathrm{CO}_{2} \mathrm{~Pa}_{\mathrm{n}} \mathrm{CO}_{2} \mathrm{VT}_{\mathrm{o}}} \\
= & \frac{\mathrm{VA}_{\mathrm{n}}}{\mathrm{VT}_{\mathrm{n}}}-\frac{\mathrm{Pa}_{\mathrm{o}} \mathrm{CO}_{2} \mathrm{PA}_{\mathrm{n}} \mathrm{CO}_{2}\left(\mathrm{VT}_{\mathrm{n}}-\mathrm{VD}_{\mathrm{an}_{\mathrm{n}}}-\mathrm{VD}_{\mathrm{m}}\right)}{\mathrm{Pa}_{\mathrm{o}} \mathrm{CO}_{2} \mathrm{~Pa}_{\mathrm{n}} \mathrm{CO}_{2} \mathrm{VT}_{\mathrm{n}}} .
\end{aligned}
$$

Substituting $\left(V T_{n}-V D_{n}\right)$ for $V A_{n}$ and $\left(V T_{0}-V D_{p_{0}}\right)$ for $V A_{0}$ :

$$
\begin{aligned}
V_{D_{p_{o}}}=\frac{V T_{0}}{V T_{n}}\left[V_{D_{n}}-\frac{\mathrm{PA}_{0} \mathrm{CO}_{2} \mathrm{PA}_{\mathrm{n}} \mathrm{CO}_{2}}{\mathrm{~Pa}_{\mathrm{o}} \mathrm{CO}_{2} \mathrm{~Pa}_{\mathrm{n}} \mathrm{CO}_{2}}\right. \\
\left.\cdot\left(\mathrm{VD}_{\mathrm{an}_{\mathrm{n}}}-\frac{\mathrm{VT}_{\mathrm{n}}}{\mathrm{VT}_{\mathrm{o}}} \cdot \mathrm{VD}_{\mathrm{an}_{\mathrm{o}}}+\mathrm{VD}_{\mathrm{m}}\right)\right] .
\end{aligned}
$$

Substitution for $\mathrm{PACO}_{2}$ from equation 3 gives an equivalent equation:

$$
\begin{aligned}
& V D_{p_{o}}=\frac{V T_{0}}{V T_{n}}\left[V D_{n}-\frac{P_{E_{o}} C_{2} V T_{o}}{P_{0} C_{0}\left(V T_{o}-V D_{a_{0}}\right)}\right. \\
& \cdot \frac{\mathrm{PE}_{\mathrm{n}} \mathrm{CO}_{2} \cdot \mathrm{VT}_{\mathrm{n}}}{\mathrm{Pa}_{\mathrm{n}} \mathrm{CO}_{2}\left(\mathrm{VT}_{\mathrm{n}}-\mathrm{VD}_{\mathrm{an}_{\mathrm{n}}}-\mathrm{VD}_{\mathrm{m}}\right)} \\
& \left.\cdot\left(V_{D_{a_{n}}}-\frac{V T_{n}}{V T_{0}} \cdot V_{D_{a_{0}}}+V D_{m}\right)\right] \text {. }
\end{aligned}
$$

The validity of equations 7 and 8 can be tested by calculating $V_{D_{p_{0}}}$ for the same subjects with different $V_{D_{m}}$ 's. If the assumption holds that $f_{p}$ remains constant with added $V_{D_{m}}$, then $\mathrm{VD}_{\mathrm{p}_{\mathrm{o}}}$ (and $\mathrm{VD}_{\mathrm{p}_{\mathrm{o}}} / \mathrm{VT}_{\mathrm{o}}$ ) should remain constant.

In the routine measurement of dead space, $V_{D_{p_{0}}}$ is always calculated for $V T_{0}=V T_{n}$. If $V_{D_{a_{0}}}=V_{D_{\mathbf{a n}_{n}}}$, then equations 7 and 8 simplify to

$$
\begin{aligned}
\mathrm{VD}_{\mathrm{p}_{\mathrm{o}}}=\mathrm{VD}_{\mathrm{n}}-\left[\frac{\mathrm{PA}_{\mathrm{o}} \mathrm{CO}_{2} \mathrm{PA}_{\mathrm{n}} \mathrm{CO}_{2}}{\mathrm{~Pa}_{\mathrm{o}} \mathrm{CO}_{2} \mathrm{~Pa}_{\mathrm{n}} \mathrm{CO}_{2}}\right] \cdot \mathrm{VD}_{\mathrm{m}} \\
\mathrm{VD}_{\mathrm{p}_{\mathrm{o}}}=\mathrm{VD}_{\mathrm{n}}-\left[\frac{\mathrm{PE}_{\mathrm{o}} \mathrm{CO}_{2} \mathrm{VT}}{\mathrm{Pa}_{\mathrm{o}} \mathrm{CO}_{2}\left(\mathrm{VT}-\mathrm{VD}_{\mathrm{an}}\right)}\right. \\
\left.\cdot \frac{\mathrm{PE}_{\mathrm{n}} \mathrm{CO}_{2} \mathrm{VT}}{\mathrm{Pa}_{\mathrm{n}} \mathrm{CO}_{2}\left(\mathrm{VT}-\mathrm{VD}_{\mathrm{an}}-\mathrm{VD}_{\mathrm{m}}\right)}\right] \cdot \mathrm{VD}_{\mathrm{m}} .
\end{aligned}
$$

Since equations 9 and 10 are equations 7 and 8 at the VT and $V_{D_{a n}}$ of the measurement, experimental validation of equations 7 and 8 also validates 9 and 10 .

If it can be shown that substitution of $\mathrm{PA}_{\mathrm{A}_{n}} \mathrm{CO}_{2} / \mathrm{Pa}_{\mathrm{n}} \mathrm{CO}_{2}$ for $\mathrm{PA}_{0} \mathrm{CO}_{2} / \mathrm{Pa}_{0} \mathrm{CO}_{2}$ (and the equivalent substitution in equation 10) result in very little error, then two good working equations are

$$
\begin{aligned}
& \mathrm{VD}_{\mathrm{p}}=\mathrm{VD}_{\mathrm{n}}-\left[\frac{\mathrm{PA}_{\mathrm{n}} \mathrm{CO}_{2}}{\mathrm{~Pa}_{\mathrm{n}} \mathrm{CO}_{2}}\right]^{2} \cdot \mathrm{VD}_{\mathrm{m}} \\
& \mathrm{VD}_{\mathrm{p}}=\mathrm{VD}_{\mathrm{n}}-\left[\frac{\mathrm{PE}_{\mathrm{n}} \mathrm{CO}_{2} \cdot \mathrm{VT}}{\mathrm{Pa}_{\mathrm{n}} \mathrm{CO}_{2}\left(\mathrm{VT}-\mathrm{VD}_{\mathrm{an}}-\mathrm{VD}_{\mathrm{m}}\right)}\right]^{2} \\
& \cdot \mathrm{VD}_{\mathrm{m}} .
\end{aligned}
$$

These equations, like equations 9 and 10 , give $V_{D_{p}}$ at $V_{T_{n}}$; but they require data from only a single collection.

Measurements. $\mathrm{VD}_{\mathbf{n}}$ was measured in seven men chosen to represent a wide range of $\mathrm{VD}_{\mathrm{p}} / \mathrm{Vr}$. The men sat upright and breathed spontaneously through a rubber mouth piece and Hans-Rudolph valve with a combined $\mathrm{VD}_{\mathrm{m}}$ of $120 \mathrm{ml}$. Additional measurements were made with pipes of varying lengths and internal diameter of $2 \mathrm{~cm}$ between the mouth piece and valve. Expired gas was collected in a 350 liter gasometer. The subjects breathed through each $\mathrm{VD}_{\mathrm{m}}$ for at least $8 \mathrm{~min}$ before each measurement was begun. Arterial blood was collected from an indwelling catheter during the middle minute of a 3 min gas collection. End-tidal $\mathrm{CO}_{2}$ at the mouth and mixed expired $\mathrm{CO}_{2}$ from the gasometer were measured with an infrared $\mathrm{CO}_{2}$ meter. Alveolar $\mathrm{CO}_{2}$ plateaued for each subject. Correction was made for the volume of gas lost through the $\mathrm{CO}_{2}$ meter, and the total volume of expired gas was corrected to BTPS (body temperature, pressure, saturated with water) $\mathrm{P}_{\mathrm{CO}_{2}}, \mathrm{P}_{\mathrm{O}_{2}}$, and $\mathrm{pH}$ were measured with an Instrumentation Laboratory blood gas analyzer (Instrumentation Laboratory Inc., Lexington, Mass.). Both the infrared $\mathrm{CO}_{2}$ meter and the $\mathrm{CO}_{2}$ electrode were calibrated with the same gases, previously analyzed with the Scholander $0.5 \mathrm{~cm}^{3}$ gas analyzer. Duplicate measurements using the same $V_{D_{m}}$ were made for six of the men. The reproducibility of $\mathrm{VD}_{\mathrm{n}} / \mathrm{VT}$ was within 0.02 for five men; the sixth (C. W.) had very disparate VT's with the same $\mathrm{VD}_{\mathrm{m}}$. Of the 41 collections, one deviated inexplicably for $\mathrm{C}$. $\mathrm{O}$. from all the other results (duplicate measurement with $120 \mathrm{ml} \mathrm{VD_{m }}$ ) and was discarded; however, duplicate measurements with $218 \mathrm{ml} \mathrm{VD_{m }}$ were made with perfect agreement for $V_{D_{n}} / V T$.

Calculations. $\mathrm{VD}_{\mathrm{p}}$ (and $\mathrm{VD}_{\mathrm{p}} / \mathrm{VT}_{\mathrm{n}}$ ) were calculated for each collection using no correction $\left(\mathrm{VD}_{\mathrm{n}}\right)$, the traditional correction (equation 1), and equations 9-12. Equations 7 and 8 were 
tested by using the VT and $\mathrm{PCO}_{2}$ 's of the initial condition (with $120 \mathrm{ml} \mathrm{VD_{m }}$ ) for the "o" condition (without $V D_{m}$ ). Equations 8 and 10 include $120 \mathrm{ml} \mathrm{VD}_{\mathrm{m}}$ in the denominator of the ventilation ratio for the "o" condition. The last collection (instead of the first with the same $120 \mathrm{ml} \mathrm{VD}_{\mathrm{m}}$ ) was used to calculate $\mathrm{VD}_{\mathrm{p}_{\mathrm{o}}} / \mathrm{VT}_{\mathrm{o}}$ for $\mathrm{C}$. W., because his initial $\mathrm{VT}$ far exceeded all subsequent VT's. The mean end-tidal $\mathrm{PCO}_{2}$ was used for $\mathrm{PACO}_{2}$, and $V_{D_{a n}}$ was estimated from ideal body weight $(6,7)$. Where $\left[\mathrm{PE}_{\mathrm{CO}_{2}} \mathrm{VT} / \mathrm{PaCO}_{2}\left(\mathrm{VT}-\mathrm{VD}_{\mathrm{Dan}_{\mathrm{an}}}-\mathrm{V}_{\mathrm{D}_{\mathrm{m}}}\right)\right]$ was $>1$ (C. O.), a value of 1 was used.

Regression lines (8) for $V_{D_{p}} / V_{T}$ on $V_{D_{m}} / V T$ were calculated for each method and each subject. Comparisons of $\mathrm{VD}_{\mathrm{p}} / \mathrm{Vr}_{\mathrm{n}}$ by equations 11 with 9 and by 12 with 10 were made, and correlation coefficients $(r)$ were calculated (8). The initial

TABLE I

$V_{D_{p}} / V_{T}$ with Added $V_{D_{m}}$ Calculated by (a) No Correction for $V_{D_{m}}$, (b) Traditional Correction, (c) Equation 7, and (d) Equation 8

\begin{tabular}{|c|c|c|c|c|c|c|c|c|c|c|}
\hline $\begin{array}{l}\text { Subject, diagnosis, age, } \\
\text { height, estimated VDan }\end{array}$ & $V_{D_{m}}$ & $V_{T}$ & $\begin{array}{l}\text { Respiration } \\
\text { rate per } \\
\text { min }\end{array}$ & $\mathrm{PECO}_{2}$ & $\mathrm{PACO}_{2}$ & $\mathrm{PaCO}_{2}$ & $\begin{array}{l}\frac{V_{D_{n}}}{V T_{n}} \\
\text { (a) }\end{array}$ & $\begin{array}{l}\frac{V_{D_{p}}}{V T_{n}} \\
\text { (b) }\end{array}$ & $\begin{array}{l}\frac{V_{D_{p o}}}{V T_{o}} \\
\text { (c) }\end{array}$ & $\begin{array}{l}\frac{V_{\mathrm{p}_{\mathrm{po}}}}{\mathrm{VT}_{\mathrm{o}}} \\
\text { (d) }\end{array}$ \\
\hline & $m l$ & $m l$ & & $m m \mathrm{Hg}$ & $m m \mathrm{Hg}$ & $m m \mathrm{Hg}$ & & & & \\
\hline \multirow{6}{*}{$\begin{array}{l}\text { C. O. } \\
\text { Asthma in remission, } \\
40 \mathrm{yr}, 69 \text { inches, } \\
141 \mathrm{ml}\end{array}$} & 120 & 473 & 19.0 & 18.0 & 36.9 & 38 & 0.53 & 0.27 & 0.29 & 0.27 \\
\hline & 170 & 515 & 20.7 & 16.4 & 36.1 & 37 & 0.55 & 0.22 & 0.26 & 0.25 \\
\hline & 218 & 538 & 21.3 & 14.9 & 37.8 & 41 & 0.64 & 0.23 & 0.31 & 0.27 \\
\hline & 270 & 591 & 21.0 & 13.9 & 38.7 & 42 & 0.67 & 0.21 & 0.32 & 0.27 \\
\hline & 322 & 652 & 21.3 & 13.6 & 39.2 & 42 & 0.68 & 0.18 & 0.30 & 0.26 \\
\hline & 218 & 538 & 22.0 & 14.7 & 36.8 & 41 & 0.64 & 0.24 & 0.33 & 0.28 \\
\hline \multirow{6}{*}{$\begin{array}{l}\text { C. } \mathrm{W} \text {. } \\
\text { Emphysema-bronchitis, } \\
55 \mathrm{yr}, 67 \text { inches, } \\
130 \mathrm{ml}\end{array}$} & 120 & 891 & 10.7 & 22.4 & 37.8 & 40 & 0.44 & 0.31 & 0.42 & 0.42 \\
\hline & 170 & 696 & 14.0 & 20.2 & 37.3 & 45 & 0.55 & 0.30 & 0.43 & 0.43 \\
\hline & 218 & 649 & 16.3 & 16.8 & 34.4 & 45 & 0.62 & 0.29 & 0.45 & 0.43 \\
\hline & 270 & 732 & 14.3 & 16.8 & 36.9 & 45 & 0.63 & 0.26 & 0.44 & 0.42 \\
\hline & 322 & 689 & 16.0 & 14.9 & 36.9 & 46 & 0.67 & 0.21 & 0.42 & 0.35 \\
\hline & 120 & 518 & 16.7 & 19.0 & 34.4 & 44 & 0.57 & 0.33 & 0.42 & 0.40 \\
\hline \multirow{6}{*}{$\begin{array}{l}\text { J. R. } \\
\text { Bronchitis-emphysema, } \\
70 \mathrm{yr}, 66 \text { inches, } \\
120 \mathrm{ml}\end{array}$} & 120 & 890 & 9.7 & 17.8 & 33.5 & 41 & 0.57 & 0.43 & 0.48 & 0.52 \\
\hline & 170 & 800 & 13.0 & 17.3 & 30.9 & 42 & 0.59 & 0.38 & 0.45 & 0.50 \\
\hline & 218 & 890 & 11.7 & 16.3 & 32.8 & 42 & 0.61 & 0.37 & 0.46 & 0.52 \\
\hline & 270 & 840 & 14.0 & 14.3 & 33.6 & 43 & 0.67 & 0.35 & 0.46 & 0.54 \\
\hline & 322 & 900 & 14.0 & 13.0 & 32.0 & 43 & 0.70 & 0.34 & 0.48 & 0.57 \\
\hline & 120 & 730 & 13.3 & 18.2 & 30.4 & 40 & 0.55 & 0.38 & 0.42 & 0.47 \\
\hline \multirow{6}{*}{$\begin{array}{l}\text { M. C. } \\
\text { Emphysema-bronchitis, } \\
56 \mathrm{yr}, 69.5 \text { inches, } \\
144 \mathrm{ml}\end{array}$} & 120 & 692 & 22.0 & 19.1 & 32.0 & 45 & 0.58 & 0.40 & 0.49 & 0.50 \\
\hline & 170 & 694 & 24.0 & 16.4 & 29.6 & 42 & 0.61 & 0.37 & 0.49 & 0.49 \\
\hline & 218 & 759 & 21.0 & 13.5 & 27.7 & 40 & 0.66 & 0.37 & 0.53 & 0.54 \\
\hline & 270 & 734 & 21.0 & 14.5 & 31.6 & 42 & 0.66 & 0.29 & 0.47 & 0.47 \\
\hline & 322 & 823 & 21.0 & 13.4 & 29.8 & 43 & 0.69 & 0.30 & 0.51 & 0.51 \\
\hline & 120 & 727 & 21.7 & 15.5 & 25.9 & 37 & 0.58 & 0.42 & 0.51 & 0.51 \\
\hline \multirow{6}{*}{$\begin{array}{l}\text { H. V. } \\
\text { Bronchitis-emphysema, } \\
56 \mathrm{yr}, 73 \text { inches, } \\
165 \mathrm{ml}\end{array}$} & 120 & 1013 & 21.7 & 16.3 & 27.1 & 40 & 0.59 & 0.47 & 0.53 & 0.55 \\
\hline & 170 & 910 & 20.3 & 16.7 & 28.1 & 41 & 0.59 & 0.40 & 0.49 & 0.51 \\
\hline & 218 & 979 & 18.7 & 14.9 & 27.3 & 40 & 0.63 & 0.40 & 0.52 & 0.55 \\
\hline & 270 & 1043 & 18.3 & 15.6 & 28.4 & 39 & 0.60 & 0.35 & 0.48 & 0.51 \\
\hline & 322 & 1162 & 17.3 & 14.6 & 28.4 & 40 & 0.63 & 0.35 & 0.51 & 0.54 \\
\hline & 120 & 1091 & 19.0 & 15.3 & 24.9 & 36 & 0.58 & 0.47 & 0.53 & 0.55 \\
\hline \multirow{6}{*}{$\begin{array}{l}\text { E. B. } \\
\text { Emphysema-bronchitis, } \\
56 \mathrm{yr}, 69 \text { inches, } \\
141 \mathrm{ml}\end{array}$} & 120 & 580 & 19.0 & 16.3 & 32.4 & 59 & 0.72 & 0.52 & 0.66 & 0.67 \\
\hline & 170 & 636 & 19.3 & 16.7 & 36.6 & 61 & 0.73 & 0.46 & 0.65 & 0.66 \\
\hline & 218 & 642 & 16.7 & 15.6 & 41.4 & 65 & 0.76 & 0.42 & 0.65 & 0.68 \\
\hline & 270 & 712 & 16.0 & 15.1 & 38.2 & 64 & 0.77 & 0.39 & 0.66 & 0.67 \\
\hline & 322 & 729 & 16.0 & 14.0 & 38.7 & 64 & 0.78 & 0.34 & 0.65 & 0.65 \\
\hline & 120 & 556 & 20.7 & 16.0 & 32.3 & 57 & 0.72 & 0.50 & 0.65 & 0.66 \\
\hline \multirow{4}{*}{$\begin{array}{l}\text { L. H. } \\
\text { Embolism-emphysema, } \\
62 \mathrm{yr}, 63.5 \text { inches, } \\
113 \mathrm{ml}\end{array}$} & 120 & 478 & 33.0 & 7.1 & 16.8 & 59 & 0.88 & 0.63 & 0.86 & 0.87 \\
\hline & 170 & 470 & 34.3 & 6.5 & 19.6 & 63 & 0.90 & 0.54 & 0.87 & 0.88 \\
\hline & 218 & 501 & 36.0 & 5.9 & 22.0 & 62 & 0.90 & 0.47 & 0.86 & 0.88 \\
\hline & 270 & 507 & 37.3 & 5.3 & 23.0 & 63 & 0.92 & 0.38 & 0.86 & 0.87 \\
\hline
\end{tabular}




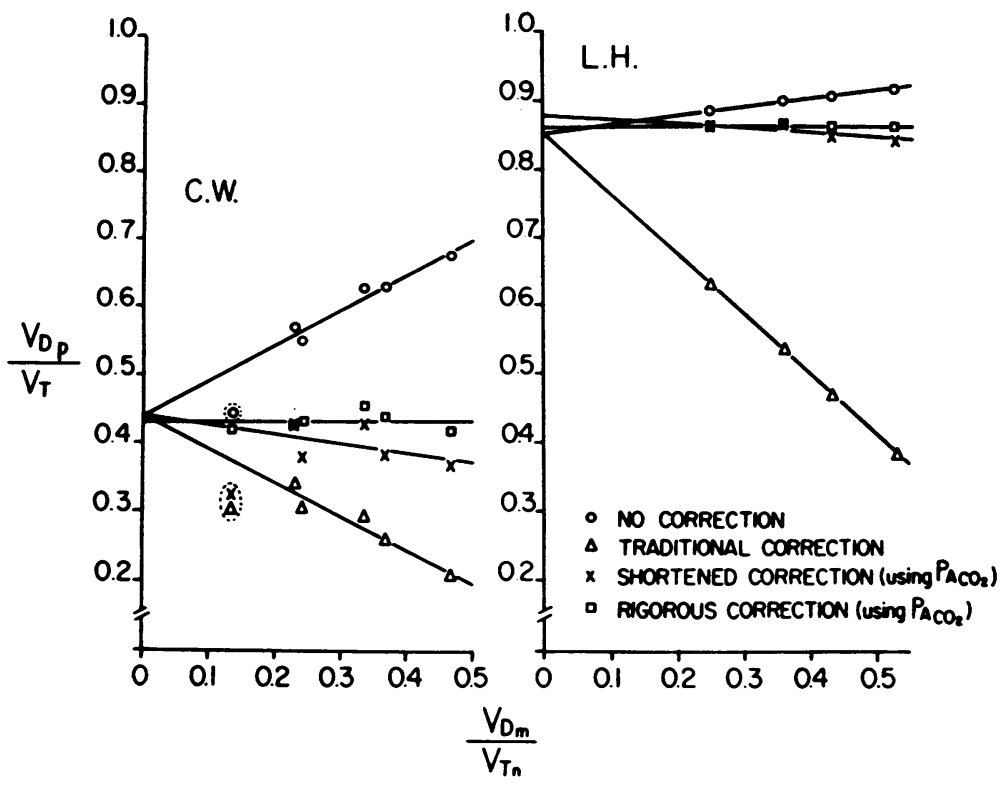

FIGURE 1 The change of $\mathrm{VD}_{\mathrm{p}} / \mathrm{VT}$ with added $\mathrm{VD}_{\mathbf{m}}$ for $\mathrm{C}$. W. and L. H. Values plotted are by $(a)$ no correction for $\mathrm{VD}_{\mathrm{m}},(b)$ traditional correction (equation 1), (c) shortened equation 11, and $(d)$ rigorous equation 7. Extrapolation of the regression lines to $\mathrm{VD}_{\mathrm{m}}=0$ indicates the approximate $V_{D_{p}} / V T$ of the subject when breathing without $V_{D_{m}}$. The decrease of $V_{D_{p}} / V_{T}$ by equation 11 represents for $C$. W. a true decrease as a result of the increased VT response to added $V D_{m}$ (see text). The three encircled points were calculated for an initial VT $200 \mathrm{ml}$ greater than any succeeding measurement. These data were not used in the calculation of regression lines because of the unusually large VT.

measurements were not included in these correlations, because $\mathrm{PA}_{\mathrm{n}} \mathrm{CO}_{2} / \mathrm{Pa}_{\mathrm{n}} \mathrm{CO}_{2}$ and $\mathrm{PA}_{0} \mathrm{CO}_{2} / \mathrm{Pa}_{0} \mathrm{CO}_{2}$ (and their equivalents in equations 10 and 12) were identical.

\section{RESULTS}

Fig. 1 shows $V_{D_{p}} / \mathrm{VT}$ calculated by four methods for C. W. and L. H. The intercepts of the regression lines at $V_{D_{m}}=0$ indicate the approximate $V_{D_{p}} / V T$ ratios of the patients when breathing without $V_{D_{m}}$. As $V_{D_{m}} / V_{T_{n}}$ increases, $V_{D_{n}} / V_{T_{n}}$ and the traditional correction for $\mathrm{C}$. $\mathrm{W}$. appear to deviate equally from the intercept value of 0.44 ; neither gives the proper value. For L. H. (pulmonary embolism), the increase in $\mathrm{VD}_{\mathrm{n}} / \mathrm{VT}_{\mathrm{n}}$ is only 0.06 with 0.53 added $\mathrm{VD}_{\mathrm{m}} / \mathrm{VT}_{\mathrm{n}}(270 \mathrm{ml}$ $\left.\mathrm{VD}_{\mathrm{m}}\right)$; when the traditional correction is used, $\mathrm{VD}_{D_{\mathbf{p}}} / \mathrm{VT}$ is 0.38 , a gross underestimation of the 0.85 intercept. Table I (column b) shows for the group that underestimation of $V_{D_{p}} / V T$ by the traditional correction increased as alveolar dead space increased.

Equations 7 and 8 give $V D_{p o}$ at a constant $V T$ (the assumed value for $\mathrm{VT}_{\mathrm{o}}$ ). In Fig. 1 the results from equation 7 (rigorous correction using $\mathrm{PACO}_{2}$ ) produce horizontal regression lines for both patients. This constancy in $\mathrm{VD}_{\mathrm{po}} / \mathrm{VT}_{\mathrm{o}}$ is shown in Table $\mathrm{I}$ for each of the seven subjects and for both equations. For six of the seven men the intercepts of the regression lines for equations
7 and 8 at zero $V D_{m}$ are within 0.02 of those for $\mathrm{VD}_{\mathrm{n}} / \mathrm{VT}_{\mathrm{n}}$.

Equations 9 and 10 calculate $V_{D_{p}} / \mathrm{VT}$ at the $\mathrm{VT}$ of the measurement (rather than at a constant VT as in equations 7 and 8 ). With added $V_{D_{m}}$ the subjects tended to increase $\mathrm{VT}$ slightly and $\mathrm{VD}_{\mathrm{p}} / \mathrm{VT}$ by equations 9 and 10 decreases accordingly. The decrease for $\mathrm{C}$. W. in Fig. 1 by equation 11 is essentially the same as by equation 9. This slight decrease represents a true decrease in $\mathrm{VD}_{\mathrm{p}} / \mathrm{VT}$ with spontaneously increasing $\mathrm{VT}(1,2)$. The encircled measurement in Fig. 1 (VT $373 \mathrm{ml}$ greater than the repeat with the same $V D_{m}$ ) is further evidence of this true decrease.

Values for $V_{D_{p}} / V_{T}$ by equations 11 and 12 agree within 0.02 of the values by the more rigorous equations 9 and 10 in 32 of 33 comparisons for both pairs of equations. The correlations are extremely high $(r=0.998$ for each comparison).

\section{DISCUSSION}

Dead space in the original Bohr equation (9) or measured by Fowler's method (10) is $V D_{a n}+V D_{m}$, i.e. mechanical dead space is simply an extension of $\mathrm{VD}_{\mathrm{D}_{\mathrm{an}}}$. However, physiological dead space includes alveolar dead space $\left(V_{D_{\mathbf{a l v}}}\right)$ which is a functional volume (11), 
defined as the difference between physiological and anatomical dead space (12). $V_{D_{a l v}}$ is primarily caused by reduced perfusion of alveoli relative to their ventilation (13). If $\mathrm{VD}_{\mathrm{m}}$ were simply an extension of $\mathrm{VD}_{\mathrm{an}}$ during measurement of $V_{D_{n}}, V_{D_{a l v}}$ would also equal $V D_{n}-V D_{a n}-V D_{m}$. The fact that $V D_{p}$ is underestimated when all of $V_{D_{m}}$ is subtracted from $V_{D_{n}}$ indicates that this is not so. As $V_{D_{a l v}}$ increases an increasingly smaller fraction of dead space gas from $V_{D_{m}}$ is inhaled into the perfused areas of the lung where it decreases effective ventilation (increases dead space). In the nonperfused alveoli $\mathrm{VD}_{\mathrm{m}}$ gas has little effect on dead space, i.e. effective ventilation cannot be decreased below 0 . The nonperfused alveoli do contribute indirectly to gas exchange by exhaling part of the $\mathrm{CO}_{2}$ inhaled from $\mathrm{VD}_{\text {an }}$ and $V D_{m}$ in the previous breath (12). When $V_{D_{m}}$ is added, a smaller volume of this gas escapes to the outside, but its $\mathrm{CO}_{2}$ concentration is greater. Equations 7 and 8 take all these changes into account.

The nearly horizontal slopes of $\mathrm{VD}_{\mathrm{p}_{\mathrm{o}}} / \mathrm{VT}_{\mathrm{o}}$ on $\mathrm{VD}_{\mathrm{m}} / \mathrm{VT}_{\mathrm{T}}$ and the agreement of the intercepts at $V_{D_{m}}=0$ with those for $\mathrm{VD}_{\mathrm{n}} / \mathrm{VT}$ indicate the validity of equations 7 and 8 and of the assumption used in their derivation (that $f_{p}$ does not change significantly with added $V D_{m}$ ).

Equations 11 and 12 are good working equations to use with data from a single collection. As with the traditional correction for $\mathrm{VD}_{\mathrm{m}}$, they apply only to the conditions $\left(\mathrm{VT}_{\mathrm{n}}\right.$, posture, spontaneous or assisted ventilation, etc.) of the measurement. The substitutions of $\mathrm{PA}_{\mathrm{n}} \mathrm{CO}_{2} / \mathrm{Pa}_{\mathrm{n}} \mathrm{CO}_{2}$ for $\mathrm{PA}_{\mathrm{A}_{0} \mathrm{CO}_{2}} / \mathrm{Pa}_{0} \mathrm{CO}_{2}$, and the equivalent substitution using $\mathrm{VD}_{\text {an }}$ introduce little error as shown by the comparisons of equation 11 with 9 and 12 with 10.

Since the ratio within the brackets of equations 11 and 12 is the ratio of effective to total alveolar ventilation, it can never be $>1$. When the calculated $\mathrm{PACO}_{2} /$ $\mathrm{PaCO}_{2}$ in equation 11 , or the equivalent ratio in equation 12 is $>1$, simply subtract $V D_{m}$ from $V D_{n}$.

Both equations 11 and 12 can be applied at large tidal volumes. However, if alveolar $\mathrm{CO}_{2}$ does not plateau, e.g., during the hyperventilation of exercise, then equation 12 using $V_{D_{a n}}$ is preferable. Any of several equations from the literature can be used for estimating $V_{D_{a n}}$ $(14,15)$. When comparing $V_{D_{p}} / V T$ during exercise with rest, $3 \mathrm{ml}$ should be added to the estimated $V_{D_{a n}}$ for every $100 \mathrm{ml}$ over the subject's resting VT $(1,16)$. When VT is very small, e.g., $<300 \mathrm{ml}$ for normal adults, correction for $V_{D_{m}}$ is not dependable because alveolar ventilation begins before washout of $V_{D_{a n}}$ and $V_{D_{m}}$ is complete (17).

Clinically, $\mathrm{VD}_{\mathrm{p}} / \mathrm{VT}$ at normal tidal volumes gives a better index of alveolar dead space than do arterialalveolar $\mathrm{CO}_{2}$ gradients when there is coexistent uneven ventilation. In addition, hyperventilation of exercise can be used to distinguish the normal decrease of
$\mathrm{VD}_{\mathrm{p}} / \mathrm{VT}$ from the increased $\mathrm{VD}_{\mathrm{p}} / \mathrm{VT}$ accompanying pulmonary vascular occlusion (2). Since hyperventilation requires low resistance breathing valves having significant dead space, the proper correction for $V_{D_{m}}$ is important.

\section{ACKNOWLEDGMENTS}

We are grateful to Mrs. Roberta Trager and Mrs. Ardis Clark for technical assistance, to Mr. Frank Hale for critical review and assistance with statistical computations, and to Mrs. Kim Ash for typing the manuscript.

\section{REFERENCES}

1. Lifshay, A., C. W. Fast, and J. B. Glazier. 1971. Effects of changes in respiratory pattern on physiological dead space. J. Appl. Physiol. $31: 478$.

2. Nadel, J. A., W. M. Gold, and J. H. Burgess. 1968. Early diagnosis of chronic pulmonary vascular obstruction. Value of pulmonary function tests. Am. J. Med. 44: 16.

3. Enghoff, H. 1938. Volumen inefficax. Bemerkungen zur Frage des Schädlichen Raumes. Upsala Läkarefören. Förh. $44: 191$.

4. Suwa, K., and H. H. Bendixen. 1968. Change in $\mathrm{PaCO}_{2}$ with mechanical dead space during artificial ventilation. J. Appl. Physiol. 24: 556.

5. Julian, D. G., D. M. Travis, E. D. Robin, and C. H. Crump. 1960. Effect of pulmonary artery occlusion upon end-tidal $\mathrm{CO}_{2}$ tension. J. Appl. Physiol. 15: 87 .

6. Radford, E. P., Jr. 1955. Ventilation standards for use in artificial respiration. J. Appl. Physiol. $7: 451$.

7. Spector, W. S., editor. 1956. Handbook of Biological Data. W. B. Saunders Company, Philadelphia. 181.

8. Snedecor, G. W., and W. G. Cochran. 1967. Statistical Methods. Iowa State University Press, Ames. 6th edition. 135,172 .

9. Bohr, C. 1891. Ueber die Lungenathmung. Skand. Arch. Physiol. 2: 236.

10. Fowler, W. S. 1948. Lung function studies. II. The respiratory dead space. Am. J. Physiol. 154: 405.

11. Folkow, B., and J. R. Pappenheimer. 1955. Components of the respiratory dead space and their variation with pressure breathing and with bronchoactive drugs. J. Appl. Physiol. 8: 102 .

12. Severinghaus, J. W., and M. Stupfel. 1957. Alveolar dead space as an index of distribution of blood flow in pulmonary capillaries. J. A ppl. Physiol. 10: 335 .

13. Riley, R. L., and A. Cournand. 1949. "Ideal" alveolar air and the analysis of ventilation-perfusion relationships in the lungs. J. Appl. Physiol. $1: 825$.

14. Hart, M. C., M. M. Orzalesi, and C. D. Cook. 1963. Relation between anatomic respiratory dead space and body size and lung volume. J. A ppl. Physiol. 18: 519.

15. Wood, L. D. H., S. Prichard, T. R. Weng, K. Kruger, A. C. Bryan, and H. Levison. 1971. Relationship between anatomic dead space and body size in health, asthma, and cystic fibrosis. Am. Rev. Respir. Dis. $104: 215$.

16. Shepard, R. H., E. J. M. Campbell, H. B. Martin, and T. Enns. 1957. Factors affecting the pulmonary dead space as determined by single breath analysis. J. Appl. Physiol. $11: 241$.

17. Briscoe, W. A., R. E. Forster, and J. H. Comroe, Jr. 1954. Alveolar ventilation at very low tidal volumes. J. Appl. Physiol. 7: 27. 